\title{
Research on the Design of Agricultural Machinery Products Based on Ecological Thinking_-Taking Sunflower Seedling Machine as an Example
}

\author{
Zhang Zhongyue ${ }^{1, a}$, Liu Wenming ${ }^{* 2, b}$ \\ ${ }^{1}$ JiLin University of Finance and Economics, Changchun, China \\ ${ }^{2}$ Shenyang Jianzhu University, Shenyang, China
}

\begin{abstract}
This article describes the basic content and expression of ecological thinking, and explains how to apply the specific aspects of ecological thinking involved in high-efficiency, energy-saving, and environmental protection in the field of agricultural machinery design. This paper take the sunflower deseeding machine as an example, carry out innovative design research based on ecological thinking. Through the research and arrangement of relevant design elements and design principles and design practice, it provides new design ideas for the innovative design of sunflower threshing machines, and reflects the guiding role and application value of ecological thinking in agricultural machinery products.
\end{abstract}

\section{Introduction}

The rapid development of the industrial revolution has accumulated a large amount of social material wealth and created a vigorous industrial civilization. This achievement is based on the plundering of resources by mankind. With the continuous deepening of the industrial process, the global economic crisis and the emerging ecological dilemmas herald the arrival of the short-term era of industrial civilization [1]. At this time, the proposal of ecological thinking provides a brand-new mode of thinking for solving the ecological problems faced by our country in the development process and the ecological problems that have appeared frequently in the world. It is also a great development on the road of socialist construction in our country.

\section{Basic overview of ecological thinking}

The relationship between man and nature has always been the core of the Marxist view of nature. The unbalanced development model of the two will inevitably cause the alienation of the relationship. To get rid of this alienation, it is necessary to seek the "harmony" of the relationship between man and nature. The "harmony" here emphasizes a moderate relationship between quality and quantity, that is, the relationship between man and nature must be maintained within the range of "balance", and only within this range, the relationship between man and nature and society and nature Only when the relationship between human beings can reach a balanced state, this is the fundamental purpose of the construction of ecological civilization, and it is also the direction of the future development of human civilization.

\section{Design Thinking of Agricultural Machinery Products under the Guidance of Ecological Thoughts}

Based on the guidance of ecological thinking, designers apply the harmonious, unified, organic, and overall ecological concept of man and nature to transform industrial civilization, requiring us to consider the natural ecological environment as the object of thinking, and through product innovation and design methods, in energy conservation, Under the premise of specific environmental performance, design high-efficiency agricultural machinery products suitable for my country's agricultural development. To achieve the purpose of saving resources, protecting the ecology, and alleviating the contradiction between man and nature. Synchronize economic development with environmental protection, and achieve a dynamic balance between the two.

\section{The related theory of sunflower deseeding machine product design}

In recent years, sunflower, as a water-saving and drought-resistant economic crop, has been planted in large areas in the western and northern regions and has achieved good economic benefits. Deseeding is a key process in the production and processing of sunflower. If the freshly picked wet sunflower cannot be deseeded in time, the sunflower pan will quickly become hot and rot. Especially in rainy weather, the rate of rot will be faster, causing great 
damage to the growers. If you rely on manpower to deseed, you need a lot of people to work at the same time to have a higher efficiency, wasting manpower resources. At present, the development of sunflower deseeding machines in my country is slow and the popularization rate is very low, which has caused farmers to be unable to improve the efficiency of deseeding, restricting the productivity of sunflower seeds, and affecting the improvement of economic benefits. Therefore, it is necessary to carry out research on the transformation of sunflower deseeding machines [4].

\subsection{TRIZ Innovation Theory}

TRIZ theory is a very effective theory in product innovation. It can provide many convenient methods for product design, standardize people's design ideas, reduce the occurrence of errors, and improve the efficiency of innovation. This research is to innovate on the basis of the existing sunflower deseeding machine. With the theoretical support of TRIZ theory, the design ideas can be more clarified, the most suitable design method can be found in the system, and each step will be followed. Get the optimal solution to improve the deseed efficiency of sunflower deseed stage [5].

\subsection{Ergonomics}

Ergonomics is the study of human factors such as physiology, anatomy, and psychology in a certain working environment; the study of the interaction between humans and machines and the environment; the study of how people consider the unity of work, life and rest the subject of work efficiency, human health, safety and comfort. Ergonomics is the science of designing and optimizing the relationship between man-machine-environment systems based on human characteristics. Its main purpose is to enable people to live a healthy, safe and comfortable life and work effectively. Among them, the safety and reliability of the system, especially human health and safety, should be listed as the first issues to be considered in the design.

As an agricultural machine, the existing sunflower deseeding machine pays more attention to functionality. Talking about its appearance, it is just a simple "protective cover" made of iron sheet. Sharp iron sheet edges and exposed parts running at high speed are available at any time. The operator poses a safety threat. In addition, the height of the feeding inlet and the height of the collection device are not large enough to meet the human-machine size. This research needs to conduct an ergonomic analysis of the two structures and design a reasonable size.

\subsection{The Law of Formal Beauty}

The law of formal beauty is an abstract concept and summary of the appearance of beauty. The law of formal beauty is an important part of the aesthetic category. Now it has become the basic law of aesthetics and the main basis for people to create beauty. The law of formal beauty mainly includes seven aspects: unity and change, symmetry and balance, contrast and harmony, rhythm and rhythm, dynamic and static, organization and repetition, and overall and partial. At present, the appearance of the existing sunflower deseeding machine has almost no aesthetic feeling and is a purely functional product, but in fact, agricultural machinery can also have a formal aesthetic feeling. This topic will modify the appearance of the sunflower deseeding machine according to the law of form the goal of unifying function and form [6].

\section{Research on the Reform Design of Sunflower Seedling Machine Based on Ecological Thought}

\subsection{Design Requirements and Related Issues of Sunflower Deseeding Machine}

The working principle of the sunflower deseeding machine is to feed the sunflower plate from the feed port into the machine. After entering the deseed device, it is firstly rubbed and then beaten to meet the deseeding requirements. The fallen sunflower seeds enter the cleaning through the concave grid. The selection device, after grading and screening, achieves the separation of sunflower seeds and impurities, and finally the sunflower disk with the seeds removed is discharged out of the machine from the discharge port.

The factors that affect the working efficiency of the sunflower deseeding machine are complex and diverse. In addition to the high labor cost and the low degree of machine automation, the most important factor is the deseeding efficiency of the sunflower deseeding machine itself. The low removal rate, high crushing rate and low cleaning degree are three factors that directly affect the deseeding efficiency of the deseeding device.

\subsection{Design Guidelines}

The application of ecological thinking in agricultural machinery products is reasonable and inevitable. It is a people-oriented, industrial optimization, resource conservation, efficient output, and environmentally friendly green development strategy. It is also a green development strategy that achieves industrial prosperity, ecological livability, effective governance, and the only way to a rich life.

When designing the sunflower deseeding machine, the working principle and key components of the deseed device, separation device and transmission device of the sunflower deseeding machine are studied. Based on the mechanical design principle and ergonomics, the effect of the deseed roller is affected by analysis The main design parameters of each component are determined accordingly, and the value ranges of the relevant parameters of each component are determined accordingly, so as to lay a solid theoretical basis for the design and research of the key structure, and finally design a sunflower deseeding machine that meets the design requirements.

This research mainly focuses on the design of the conveyor, deseed device and cleaning device of the 
sunflower deseeding machine. From the conveyor track, the length of the deseed roller, the number of nails, the shape of the concave grid, the number of the concave grid, and the size of the grading screen Carry out theoretical research and analysis on the style and other aspects, and strive to meet the process requirements of farmers in the de-seed rate, de-cleaning rate, and productivity, and be separated cleanly to avoid the blocking of the deseed device caused by the sunflower plate and reduce the user's burden. Energy consumption improves the deseeding effect of sunflower seeds. The ergonomic dimensions and ergonomic factors of the sunflower seeding machine are analyzed, and the appearance of the sunflower seeding machine is redesigned through the use of the law of formal beauty to make it more in line with the aesthetic rules and more beautiful.

\section{Design and Practice of Sunflower Seedling Machine Based on Ecological Thought}

\subsection{Design of the Transformation of the Deseed Roller of the Main Components of the Sunflower Deseed Machine}

Types of deseed rollers: The core structure of the deseed device is the deseed roller. The current deseed rollers are divided into kneading sunflower deseed rollers and percussive sunflower deseed rollers. The surface of the kneading deseed roller is textured Made of rubber material, the working principle is to achieve the separation of sunflower seeds by rubbing between the deseed roller and the arc-shaped grid plate. The percussive sunflower deseed roller is composed of multiple nails evenly distributed on the surface of the deseed roller. The working principle is that the deseed roller with nail teeth cooperates with the concave grid plate with concave plate teeth on the surface, and the sunflower disk enters the deseed roller. The seed device is knocked and squeezed to achieve the effect of deseeding.

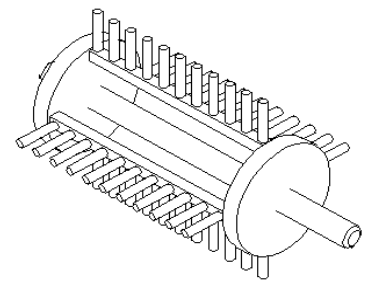

Figure 1. Percussion deseed roller

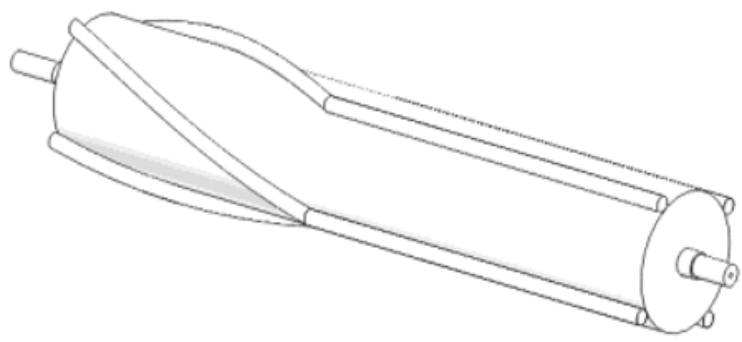

Figure 3. Spiral bar deseed roller
The current structure and shape of the deseed roller have the following forms: open deseed roller with tooth nails, closed deseed roller with tooth nails, grain deseed roller, spiral grain deseed roller. As shown in Figure 1, it is a percussion-type seed-removing roller, also known as a spike-type seed-removing roller. Figure 2 shows the rubbing type seed-removing roller, also called the grain-bar seed-removing roller. The principle of this kind of deseed roller is that the rubber deseed strip will produce a lot of friction with the sunflower plate, and the sunflower seeds are rubbed down by friction. This straight type deseed roller can achieve deseed, but it does not guide the sunflower. Because of the function of disk advancement, the phenomenon that the sunflower disk is stuck in the drum, and the time that the sunflower disk stays in the deseed device is too short, and the insufficient working time of the deseed roller is also the reason for the low removal rate.

The third type is the spiral grain deseed roller, as shown in Figure 3, it is obtained after the grain deseed roller is improved. Its biggest feature is that part of the grain rod is changed to a spiral form. The principle of this improvement is, The spiral pattern bar has the effect of pushing forward. For this kind of deseed roller, its damage rate is low. Compared with the first three types of deseed rollers, the deseed efficiency is higher, and the deseed roller is driven by a spiral. Based on the transportation principle of the sunflower disk, after the sunflower disk is deseed in the deseed device, it can be better discharged from the deseed machine through the transportation principle, which effectively avoids the problem that the sunflower disk is stuck in the deseed drum and cannot be discharged.

- Analysis of the advantages and disadvantages of the seed roller: The characteristic of the rubbing type deseed roller is that it has a soft force and does not damage the sunflower plate. After the seeds are removed, the sunflower plate is still intact. The grain breakage rate is very low and there is no interference from the debris of the sunflower plate. The cleanliness of the cleaning will also be improved. . However, the rubbing type deseed roller is easy to be unclean, and sometimes it is even necessary to repeatedly deseed to achieve a $95 \%$ removal rate.

- The percussion type deseed roller (tooth-pin type deseed roller) achieves deseeding by hitting the sunflower disk. The removal rate is much higher than that of the rubbing type deseed roller, and there is no problem of repeated deseeding. However, due to the strong force of the percussive deseed roller, it will cause great damage to the sunflower disk. After the deseed is completed, there will be almost no complete sunflower disk. Therefore, the crushing rate of sunflower seeds is relatively high. At the same time, the debris of the sunflower disk will affect the follow-up the cleansing work reduces the cleanliness of the cleansing. 
- Improved method of deseed roller: The early sunflower deseeding machine generally only installed one kind of deseed roller, and only one of the damage rate and the removal rate can be considered. The existing more advanced sunflower deseed machine has a double deseed roller structure, that is, a sunflower deseed roller. The seed machine is equipped with two deseed rollers at the same time. The sunflower plate passes through a rubbing type deseed roller to peel most of the grains that are easier to take off from the sunflower plate. At this time, only some hard-to-seed grains are left on the sunflower plate. After passing through the percussive deseed roller, the crushing rate of sunflower seeds will be greatly reduced, and the percussive deseed can achieve a higher removal rate, which will do two things with one stone.

- However, the structure of the deseed roller of the existing multiple sunflower deseed machine is that two deseed rollers are installed side by side, called a compound deseed roller. As shown in Figure 4, the rubbing type deseed roller is installed near the feeding inlet. On the side, the sunflower pan first passes through the rubbing deseed roller, and the percussive deseed roller is installed on the outlet side. After the sunflower pan passes through the percussive deseed roller, it is discharged from the outlet, and the seed mixture falls into the lower screening device for screening. Compared with a single deseed roller, this compound deseed machine not only satisfies the high detergency rate, but also ensures the low crushing rate. However, with this parallel installation structure, it is easy to cause the sunflower disk to get stuck in the middle of the two deseed rollers, and the problem that the straight deseed roller cannot guide the sunflower disk forward still exists.

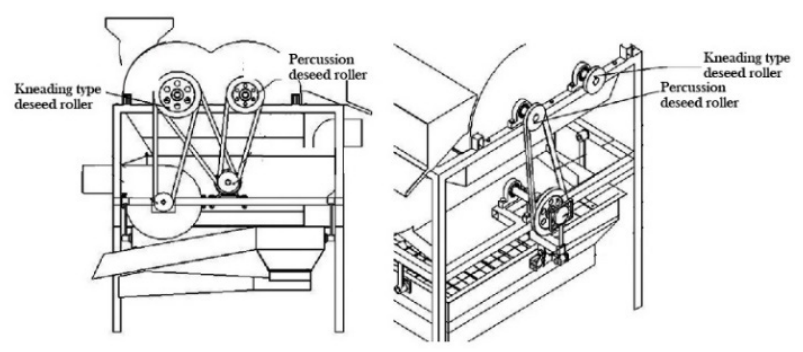

Figure 4. The structure of the double sunflower deseeding machine

The new combined deseed roller in this study is improved on the basis of the spirally propelled deseed roller, as shown in Figure 5 is the spirally propelled deseed roller, which is a relatively advanced type of deseed roller at present. The improved type of the kneading deseed roller. In addition to the deseed function of the screw-driven deseed roller, it can also transport the deseed sunflower disk to the outside of the machine by means of screw conveying based on the principle of screw pushing.

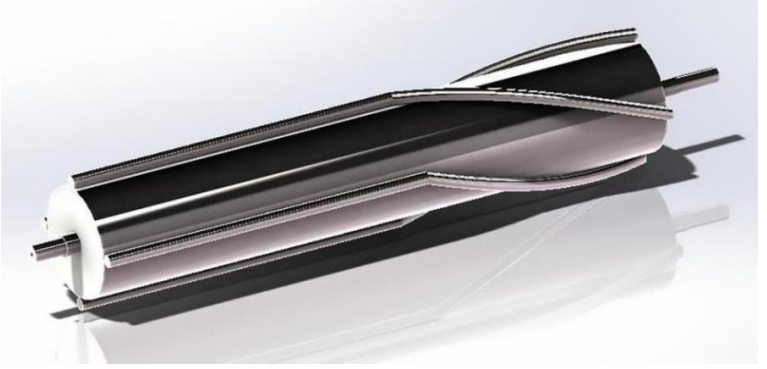

Figure 5. Spiral advancing deseed roller

The principle of the new combined deseed roller is to combine the rubbing type deseed roller and the percussion type deseed roller on the same deseed roller. This design improves the screw-driving seed-removing roller from two aspects: 1. On the basis of the screw-driving seed-removing roller, the second half is changed to a nail de-seed roller, and the specifications of the nail are reduced. Increase the number of nails and change the "percussion" to "comb brush", the purpose is to avoid breaking the sunflower disk as much as possible, improve the cleanliness of the deseed machine and reduce the crushing rate; Second, increase the total length of the deseed roller, The purpose is to extend the working time of the sunflower plate in the de-seeding device and improve the de-cleaning rate. Its structure is shown in Figure 6, including spiral bar deseed structure, spike-type deseed structure, transition belt, drum and roller shaft. The spiral grain deseed structure includes a deseed strip positioning bar and a rubbed deseed strip, and the tooth-pin type deseed structure includes a tooth nail mounting strip and a steel tooth nail. The spiral bar deseed structure is located on the left side of the drum, close to the feeding port of the deseed machine, and consists of four deseed strips spirally distributed on the drum. The deseed strips are divided into two parts, and one part is integrated with the drum. Deseed strip positioning bar, the other part is the rubbed seed strip installed on the deseed strip positioning strip. The four rubbed seed strips are made of rubber; the nail-type deseed structure is located on the right side of the drum, and this side is close to the strip The discharging port of the seed machine is uniformly annularly arrayed on the outside of the drum by four nail mounting bars, which are connected to the drum by welding, and a plurality of steel nails are arranged on the nail mounting bars.

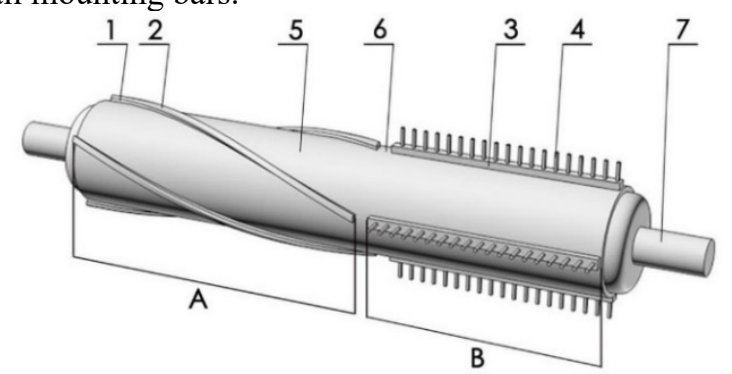

Figure 6. New combined deseed roller structure A. Spiral bar deseed structure B. Tooth nail type deseed structure 1. Deseed bar positioning bar 2. Knead deseed bar 3. Toothed nail mounting bar 4 . Steel toothed nail 5 . Roller 6 . Transition belt 7 . Roller shaft 
In the initial design, the total length of the seed-removing roller is set to $1600 \mathrm{~mm}$. The seed-removing roller is divided into two parts. The length of the rubbing type seed-removing roller is $900 \mathrm{~mm}$, and the length of the percussion type seed-removing roller is $650 \mathrm{~mm}$. The kneading deseed roller is longer than the percussive deseed roller, because the new combined deseed roller is designed based on the principle of kneading as the main and blow-assisted. Most of the grains are threshed by kneading to ensure low crushing rate. The remaining small part is completed by the percussive seed-removing roller to ensure a high removal rate.

Compared with the existing deseed roller, the advantage of this design is that the parallel structure of the existing deseed roller is changed to a kneading type deseed structure and a percussion type deseed structure combined on the same deseed roller. After the sunflower disc is rubbed and deseed by the spiral bar deseed structure, the sunflower disc is transported to the nail-type deseed structure through the spiral structure, and then the nail-type deseed structure strikes and deseeds it. Deseeding in two ways at one time effectively increases the deseeding rate and reduces the crushing rate. At the same time, the utility model avoids the phenomenon that the sunflower disk is stuck in the deseed roller.

Through the performance comparison experiment study of the new type combined deseed roller and other deseed rollers, the data comparison of the three indicators of removal rate, crushing rate and cleaning degree are obtained. As shown in Table 1, in terms of performance, the new type The combined deseed roller has significant advantages. The removal rate can reach $99 \%$ at a time, while the crushing rate is reduced to less than $1 \%$, and the cleaning degree is higher than other deseed rollers. In addition, during the experiment, there was no phenomenon that the sunflower disk was stuck in the drum, indicating that the new combined deseed roller solved the problem that the compound deseed roller was prone to failure.

Table1. Comparison of Primary Removal Rate, Crushing Rate, and Cleanliness

\begin{tabular}{|c|c|c|c|}
\hline $\begin{array}{c}\text { Deseed } \\
\text { Roller Type }\end{array}$ & $\begin{array}{c}\text { One-time } \\
\text { Removal } \\
\text { Rate }\end{array}$ & $\begin{array}{c}\text { Fragmentation } \\
\text { Rate }\end{array}$ & Cleanliness \\
\hline Kneading & $85 \%$ & $1.5 \%$ & $95 \%$ \\
\hline Percussion & $90 \%$ & $2.5 \%$ & $90 \%$ \\
\hline $\begin{array}{c}\text { Side-by-side } \\
\text { compound }\end{array}$ & $95 \%$ & $2 \%$ & $95 \%$ \\
\hline $\begin{array}{c}\text { New } \\
\text { combination }\end{array}$ & $97 \%$ & $\leqslant 1 \%$ & $98 \%$ \\
\hline
\end{tabular}

The main innovation of the de-seed device is the design of a new type of combined de-seed roller. The difference between this de-seed roller and other de-seed rollers is that it combines two types of de-seed rollers into one.

\subsection{The Appearance Design of Sunflower Deseeding Machine}

Since the end of the last century, my country has successively introduced agricultural machinery. In recent years, my country has independently innovated several sunflower threshing machines, as shown in Figure 7 is the 5TK-2.0 sunflower thresher developed in 2009. This type of sunflower threshing machine is due to It was highly practical and was loved by farmers at the time. However, the overall appearance is just a cover made to adapt to the internal structure. Many right-angled edges and corners are not beautiful and not ergonomic.

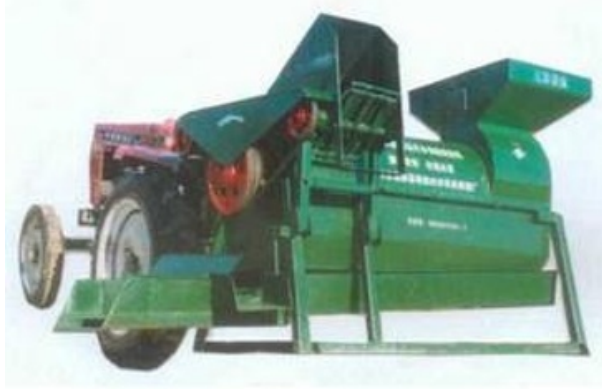

Figure 7. TK-2.0 Sunflower thresher

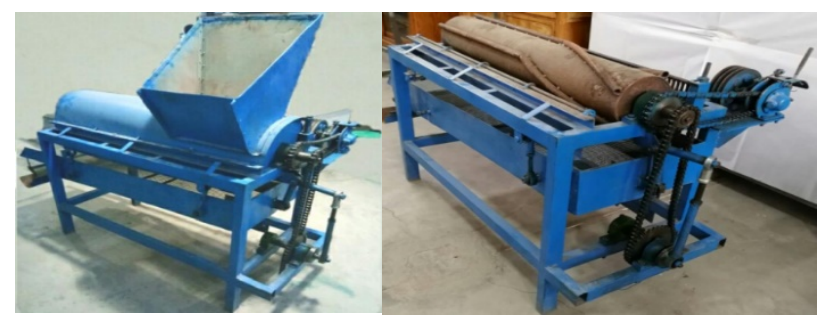

Figure 8. 5TK-1200-320 Sunflower deseeding machine

The 5TK-1200-320 sunflower deseeding machine designed in 2017, as shown in Figure 8. This model has made a leapfrog improvement on the sunflower deseed roller and solved the traditional straight type deseed roller. It is changed to a spiral type and straight. However, in terms of appearance design, simple shapes without aesthetic feeling are still adopted, and bright colors are also chosen.

Combined with the law of form beauty, the shape of the sunflower deseeding machine designed in this research is shown in Figure 9 and Figure 10 below, which mainly apply the "unity and change" and "whole and part" in the law of form beauty.

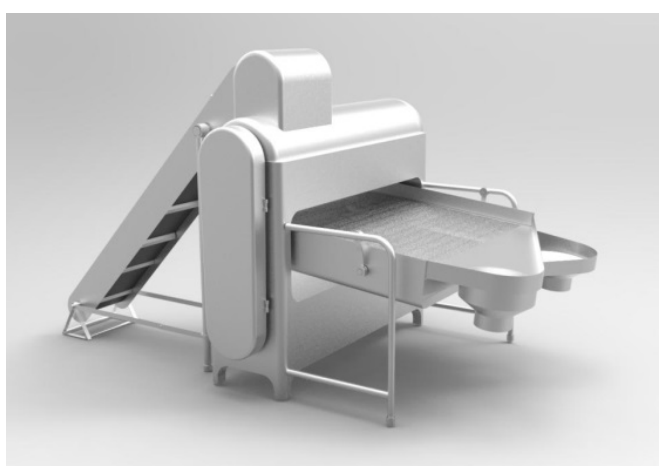

Figure 9. Project positive 


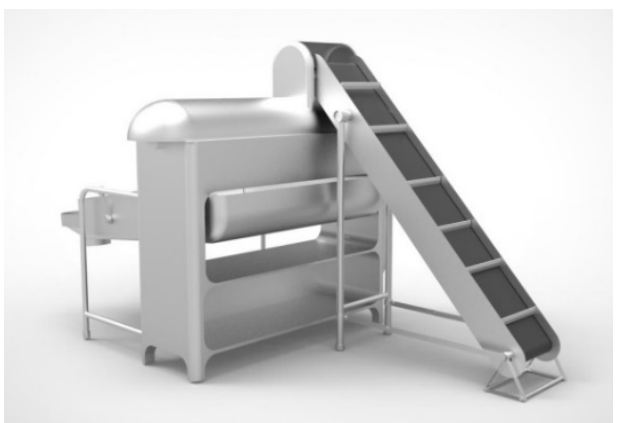

Figure 10. Back of the plan

In terms of styling, this research has the following innovations: 1. Several devices of the sunflower deseeding machine work independently, but they need to be connected by a transmission device. The transmission device of the traditional sunflower deseeding machine is exposed. Yes, it affects the appearance and is not safe. Therefore, this research designed the cover to be installed outside the transmission device, which not only improves the appearance, but also protects the operator and prevents the operator from being scratched by the conveyor belt. 2 The frame of the existing sunflower threshing machine is composed of simple square hollow columns with right-angled edges on all sides. Wherever there are right-angled edges, there will be top corners. Therefore, this study changed the right-angled edges to rounded corners. The edge weakens the visual sharpness, looks softer and more comfortable to use. 3According to the safety design and maintainability requirements of ergonomics, this research adds a shell to the rotating parts, which is closed when in use, and can be opened when repairs are needed. Through the transformation design of the shape, color, and main components of the sunflower deseeding machine, it can improve the work efficiency, reduce the labor intensity of the operator, improve the feeding efficiency, save time and effort, and greatly improve the deseeding machine. Seed efficiency increases safety. And to improve the appearance of the design, more use of curved rounded corners to improve safety and comfort.

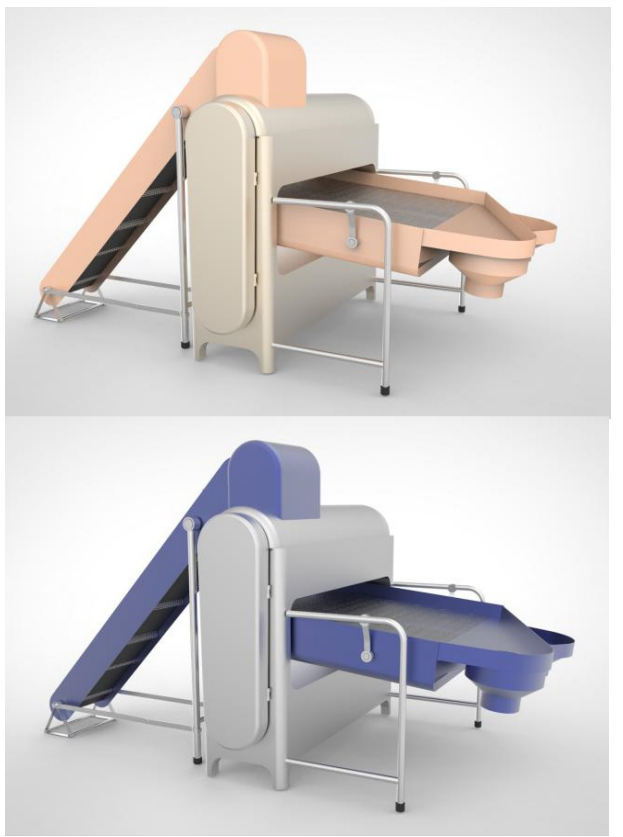

Figure 11. Color scheme

\section{7 conclusion}

Through the study of ecological thinking, this paper uses ecological thinking to lead the design thinking of agricultural machinery products, combined with the innovative design of agricultural machinery products sunflower deseed machines, and applies TRIZ innovation theory, ergonomics and the law of formal beauty to compare traditional sunflower deseed machines. Carry out innovative transformation design based on ecological thinking, and finally carry out related design practice. The new design has significantly improved the deseed efficiency and integrity of the deseed after the deseed and deseed roller is improved compared with the existing products. The product size design of the new scheme conforms to ergonomics, and the appearance and color design conform to aesthetic requirements. While greatly improving the working efficiency of the machine, it incorporates ecological design concepts such as energy saving and environmental protection. It provides a new design idea for the innovative design of sunflower deseeding machine.

\section{References}

1. Sun Jingshui. The development model of ecological agriculture in my country. Economic Research Reference, 2002(87): 32-33.

2. Feng Qigao, Mao Hanping. The development status and countermeasures of agricultural mechanization in my country. Agricultural Mechanization Research, 2010 (2).

3. Lin Gongzhen, Zhang Wencheng. Experimental study on the effect of threshing device on wheat ear cutting. Research on Agricultural Mechanization, 1988: 31-33.

4. Xu Peiqian. Comparison and selection of agricultural modernization models. Modern Economic Research, 2001 (11): 49-51.

5. Chen Shijun. Principles and Methods of Product Modeling Design. Tianjin University Press, 1994: 109-115.

6. Bai Yueshi. Analysis on the Path Choice of China's Agricultural Modernization. Beijing: China Social Sciences Press, 2004.

7. Yin Chengjie. Modern agricultural development and innovation of system mechanism. Beijing: China Agriculture Press,2013. 